Corticosteroid treatment for asthma has been regarded as potentially dangerous because of the risk of side effects. ${ }^{7}$ Studies in children with acute asthma who had received an eight day course of methylprednisolone compared with a similar group of children who had received placebo showed that in both groups adrenal responsiveness was decreased seven days after the end of treatment; the decrease was no greater in the group given methylprednisolone than in the group given placebo. ${ }^{8}$ It is thus highly unlikely that a single three day course of corticosteroids would have any adverse effect. Provided that the day to day treatment of patients with asthma is properly supervised the need for repeated courses of corticosteroids for acute attacks should be minimal.

\section{References}

Anonymous. Acute severe asthma [Editorial]. Lancet 1981;i:313-4

2 Pocock SJ. Clinical trials. Chichester: John Wiley and Sons, 1983:123-41.

Fanta CH, Rossing TH, McFadden ER. Glucocorticoids in acute asthma: a critical controlled trial. Am J Med 1983;74:845-51.

Wilson N, Silverman M. Controlled trial of slow-release aminophylline in childhood asthma: are short-term trials valid? Br Med f 1982;284:863-6.

5 Lulla S, Newcomb RW. Emergency management of asthma in children. F Pediatr 1980; 97:346-50. 6 McKenzie SA, Edmunds AT, Godfrey S. Status asthmaticus in children: a one year study. Arch Dts Child 1979;54:581-6.

Luksza AR. Acute severe asthma treated without steroids. Br 7 Dis Chest 1982;76:15-9.

8 Shapiro GG, Furukawa CT, Pierson WE, et al. Double-blind evaluation of methylprednisolone versus placebo for acute asthma episodes. Pediatrics 1983;71:510-4.

Accepted 13 May 1986

\title{
Technetium-99m autologous phagocyte scanning: a new imaging technique for inflammatory bowel disease
}

\author{
W PULlMAN, R HANNA, P SUllivaN, J A BOOTH, F LOMAS, WILliAM F DOE
}

\begin{abstract}
A method to determine the extent of active inflammatory bowel disease using selective labelling of autologous neutrophils and monocytes by phagocytosis of a technetium-99m $\left({ }^{99 m} \mathrm{Tc}\right)$ stannous oxide colloid is described. Unlike leucocyte scanning techniques using Indium-III ('"In), the ${ }^{99_{\mathrm{m}}}$ Tc colloid scan uses a cheap, readily available isotope, which specifically labels phagocytes. Scan results in 20 patients with inflammatory bowel disease were compared with barium examinations and colonoscopic appearances. There was close agreement in 15 of 20 patients as to the extent of mucosal disease. In four cases the scan showed more extensive disease than was suggested by barium examination. The scan showed terminal ileal Crohn's disease in three patients in whom the barium studies of the ileum had been reported as normal. In four patients with inactive disease and normal barium examinations no activity was seen on the scans.
\end{abstract}

The ${ }^{9 m}$ Tc phagocyte scan is a sensitive, reliable means of determining the extent of active inflammatory bowel disease and can be used to quantify disease activity.

\section{Introduction}

Previous studies of patients with inflammatory bowel disease have established that scanning after intravenous injection of autologous leucocytes labelled with radionuclides determines the extent of

\footnotetext{
Woden Valley Hospital, Australia

W PULLMAN, MB, BMEDSCI, registrar in department of medicine and clinical science

J A BOOTH, MB, FRACP, director of department of nuclear medicine

WILLIAM F DOE, FRCP, FRACP, professor and head of department of medicine and clinical science

Department of Nuclear Medicine, Royal Canberra Hospital, Australia

R HANNA, BAPPLSCI, DIPRPHARM, radiopharmacis

P SULLIVAN, MB, FRACP, staff specialist

F LOMAS, MB, FRACP, director

Correspondence to: Professor William F Doe, Department of Medicine and Clinical Science, John Curtin School of Medical Research, Australian National University, Woden Valley Hospital, Garran Act 2605 Australia.
}

active disease and facilitates objective assessment of activity. ${ }^{1.5}$ The technique is safe in the acutely ill patient ${ }^{t}$ and has proved beneficial in the study of the terminal ileum, for which conventional radiological and colonoscopic examinations are not always successful.

Most of the scanning techniques available use the radioisotope oxine labelled with indium-III ("III), which is expensive and is produced by a cyclotron and hence has limited availability. ${ }^{1.5}$ These factors mitigate against its widespread use in hospitals. Moreover,

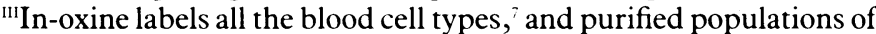
blood neutrophils must be prepared for optimal scanning. ${ }^{23}$

We recently described a new scanning technique using stannous oxide colloid labelled with technetium- $\left.99 \mathrm{~m}{ }^{4 \% \mathrm{~m}} \mathrm{Tc}\right)$ to label specifically autologous phagocytes in whole blood. ${ }^{*}$ We report the use of this readily available, inexpensive, and simple technique in scanning the intestine in patients with inflammatory bowel disease.

\section{Patients}

Twenty patients (nine men and 11 women, age range 16-70) suffering from inflammatory bowel disease (table) were studied after they had given informed consent to this study, which was approved by the Hospitals' Ethics Committee. Duration of disease ranged from two months to 15 years. Sixteen patients were diagnosed as having Crohn's disease and four as having ulcerative colitis using conventional clinical, radiological, colonoscopic, and histological criteria. Clinical disease activity was graded according to a modification of the criteria established by de Dombal as absent, mild, moderate, or severe. ${ }^{10}$ Fourteen of the 20 patients were receiving treatment with one or more of three agents: corticosteroid, sulphasalazine, and azathioprine (see table).

\section{Methods}

Autologous leucocytes (phagocytes) were selectively labelled in heparinised whole blood by phagocytosis of ${ }^{99 \mathrm{~m}} \mathrm{Tc}$ coupled to a stannous colloid ( $<2 \mu \mathrm{m}$ spheres) as described previously. ${ }^{89}$ Briefly, $20 \mathrm{ml}$ of blood was taken and incubated for one hour with $400 \mathrm{MBq}$ of ${ }^{99 \mathrm{~m}} \mathrm{Tc}$ colloid and citrate buffer. After excess colloid had been removed by centrifugation the labelled blood was returned to the patients. Immediately before abdominal scanning, which was performed at three and six hours after injection using a modern, wide field gammacamera, patients were asked to empty their bladders.

The extent of disease was determined within eight weeks of the scan by air contrast barium enema examination and, where appropriate, by small bowel 
series (nine patients). The patient in case 5 underwent only colonoscopy. Colonoscopic assessment was available for five patients. The extent of colitis or ileitis, or both, was assessed by a radiologist, who was unaware of the results of scanning. Disease was anatomically classified as occurring in one or more of five segments of the bowel: the terminal ileum or the ascending, transverse, descending, or rectosigmoid regions. Two nuclear medicine physicians, who were unaware of the diagnoses or the results of previous radiological or endoscopic assessment, independently assessed all scans.

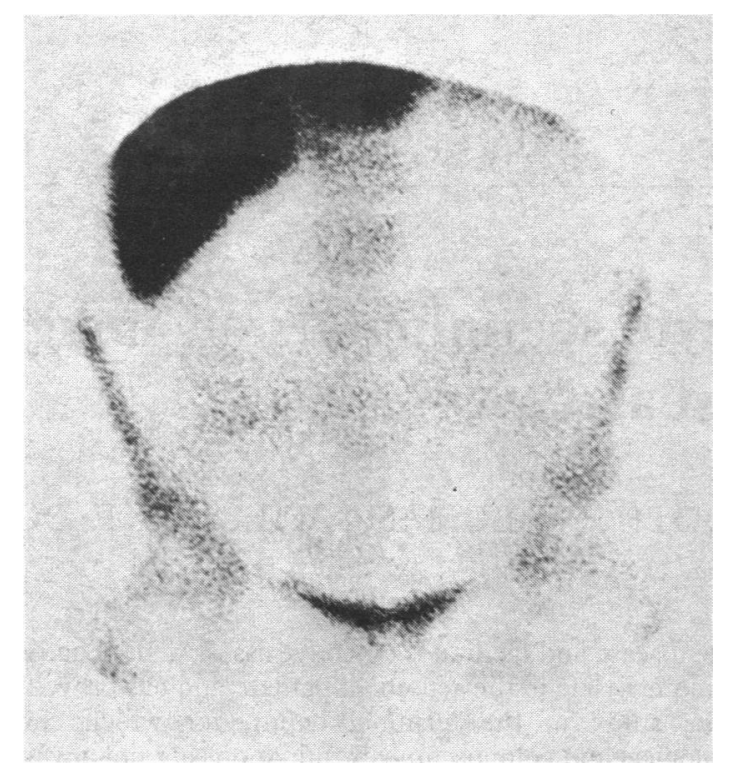

FIG 1 -Six hour ${ }^{99 m} \mathrm{Tc}$ scan showing no bowel uptake in a patient with quiescent Crohn's disease and hepatomegaly.
Radionuclide activity was reported as present or absent in each of the five segments of the bowel surveyed.

\section{Results}

$\frac{\mathscr{W}}{\mathfrak{D}}$

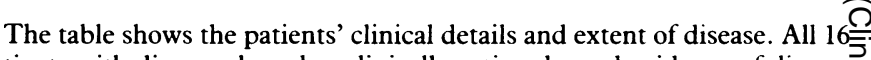
patients with disease classed as clinically active showed evidence of disease on scanning. In four patients whose inflammatory bowel disease wasp clinically inactive no activity was seen on the scans (fig l), and the barium? examinations were reported as normal in each case. In 15 of 20 patients theree was close agreement as to the segments of bowel affected. In the patient in:case 14, whose symptoms were mild, active disease of the terminal ileum and colon was detected by scanning, and the same region showed mucosal disease when viewed at barium examination. In particular, active disease inc the terminal ileum is clearly shown by scanning (fig 2). In four cases the scan showed more extensive disease or active disease in sites other than thosesuggested by barium studies (case 1). Crohn's disease of the terminal ileum was clearly shown by scanning in three patients in whom no mucosan abnormality was evident on barium examination (see table). In one patient? (case 20) who was suffering from severe ulcerative colitis the appearances of the rectosigmoid region were normal at barium examination but the $\overrightarrow{-}$ phagocyte scan showed active inflammation of the region, which was confirmed by histology (fig 3 ).

In two of the 20 patients studied the areas of disease appeared more extensive when viewed by barium examination (fig 4). Treatment within corticosteroids, azathioprine, or sulphasalazine did not affect the perform $-\omega$ ance of the scan (see table).

\section{Discussion}

The ${ }^{99_{m}}$ Tc labelled autologous leucocyte scan accurately identifies $\stackrel{\circ}{?}$ actively inflamed intestine in patients with inflammatory bowek $\overrightarrow{0}$ disease. This imaging method showed more extensive disease than barium examination in three of the 20 patients studied and was particularly valuable in identifying disease of the terminal ileum, $\overrightarrow{0}$

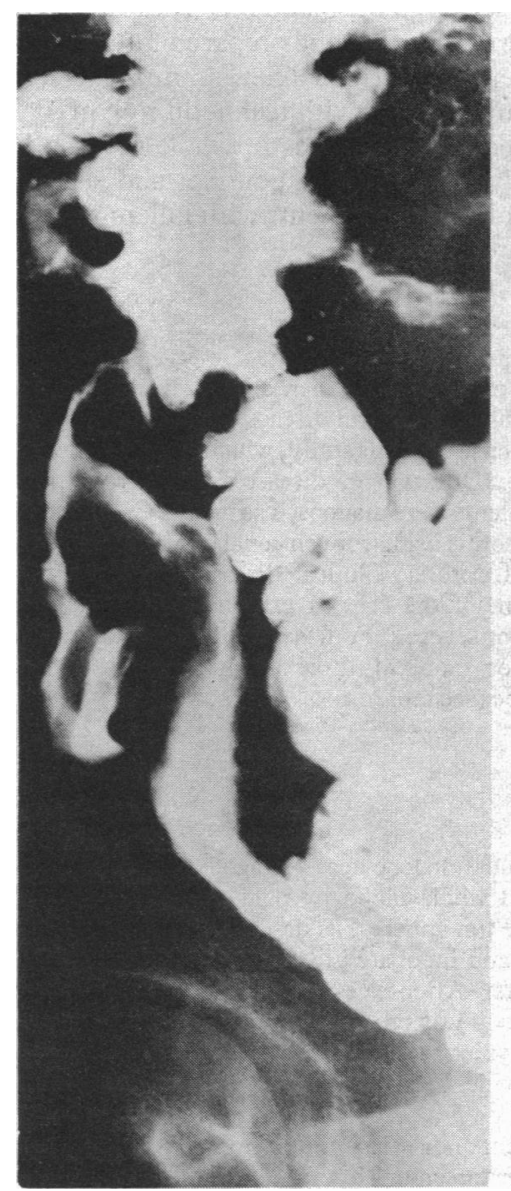

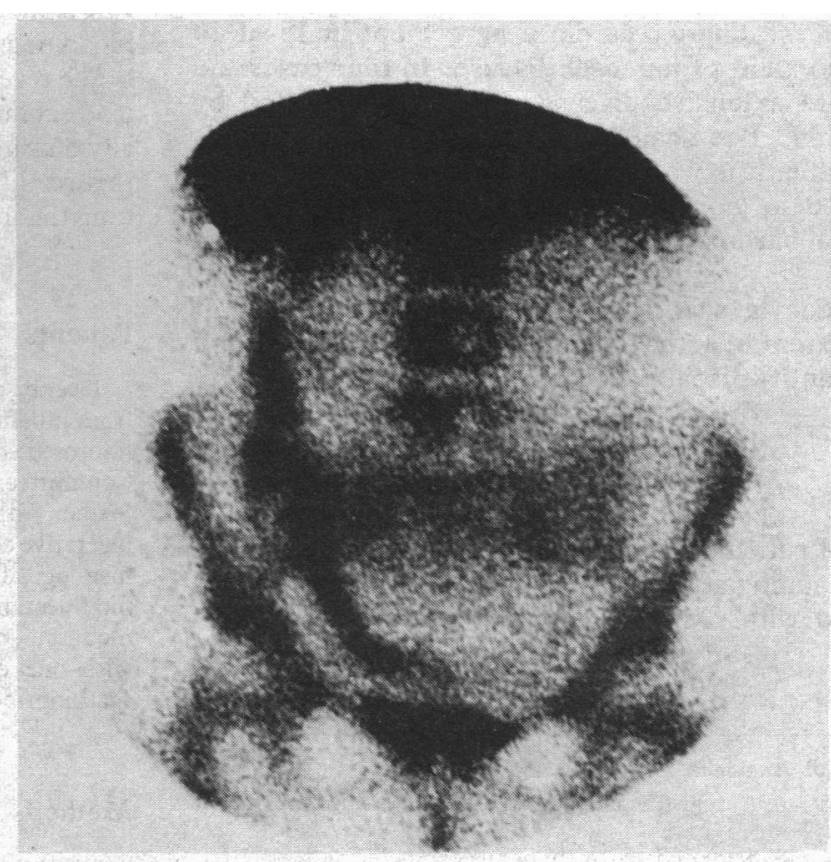

FIG 2 - Three hour ${ }^{99 m}$ Tc phagocyte scan in a patient with Crohn's disease showing active inflammation in the terminal ileum and ascending colon in agreement with radiological appearances. 
Clinical details of patients and extent of disease

\begin{tabular}{|c|c|c|c|c|c|c|}
\hline \multirow[b]{2}{*}{ Case No } & \multirow[b]{2}{*}{ Diagnosis } & \multirow[b]{2}{*}{$\begin{array}{l}\text { Disease } \\
\text { activity }\end{array}$} & \multirow[b]{2}{*}{$\begin{array}{l}\text { Activity on } \\
\text { scanning }\end{array}$} & \multicolumn{2}{|c|}{ Sites of disease ${ }^{\star}$} & \multirow[b]{2}{*}{ Treatment } \\
\hline & & & & $\begin{array}{l}\text { On radiology or } \\
\text { colonoscopy }\end{array}$ & On scanning & \\
\hline 1 & Crohn's disease & Moderate & Active & TC, DC, R & $\mathbf{T I}, \mathbf{R}$ & Prednisone $25 \mathrm{mg}$ \\
\hline 2 & Ulcerative colitis & Moderate & Active & TC, DC, R (colonoscopy) & TC, DC, R & Prednisone $60 \mathrm{mg}$ \\
\hline 3 & Crohn's disease & Severe & Active & $A C, T C, D C$ & $\mathrm{TI}, \mathrm{AC}, \mathrm{TC}, \mathrm{DC}, \mathrm{R}$ & - \\
\hline 4 & Crohn's disease & Mild & Active & TI & TI & Prednisone $20 \mathrm{mg}$ \\
\hline 5 & Crohn's disease & Moderate & Active & DC, $\mathbf{R}$ (colonoscopy) & $\mathbf{D C}, \mathbf{R}$ & - \\
\hline 6 & Crohn's disease & Moderate & Active & $\mathrm{AC}, \mathrm{TC}, \mathrm{DC}, \mathrm{R}$ & $\mathbf{D C}, \mathbf{R}$ & Prednisone $10 \mathrm{mg}$, azathioprine $50 \mathrm{mg}$ \\
\hline 7 & Crohn's disease & Moderate & Active & AC & $\mathrm{AC}$ & Prednisone $20 \mathrm{mg}$ \\
\hline 8 & Ulcerative colitis & Mild & Active & $\mathbf{R}$ (colonoscopy) & $\mathbf{R}$ & Prednisone $50 \mathrm{mg}$ \\
\hline 9 & Crohn's disease & Mild & Active & TI, AC, TC, DC & $\mathrm{TI}, \mathrm{AC}, \mathrm{TC}, \mathrm{DC}, \mathrm{R}$ & - \\
\hline 10 & Crohn's disease & Absent & Inactive & No disease (colonoscopy) & No uptake & Prednisone $5 \mathrm{mg}$ \\
\hline 11 & Crohn's disease & Moderate & Active & TI & TI & Prednisone $25 \mathrm{mg}$, azathioprine $100 \mathrm{mg}$ \\
\hline 12 & Crohn's disease & Mild & Active & TI, AC & TI, AC & - \\
\hline 13 & Crohn's disease & Moderate & Active & $\mathrm{DC}, \mathrm{R}$ & $\mathrm{DC}, \mathrm{R}$ & Hydrocortisone $300 \mathrm{mg}$ \\
\hline 14 & Crohn's disease & Mild & Active & TI, AC & TI, AC & - \\
\hline 15 & Crohn's disease & Mild & Active & TC, DC, $\mathbf{R}$ & $\mathrm{TI}, \mathrm{AC}, \mathrm{TC}, \mathrm{DC}, \mathbf{R}$ & Prednisone $50 \mathrm{mg}$, azathioprine $100 \mathrm{mg}$ \\
\hline 16 & Crohn's disease & Absent & Inactive & No disease & No uptake & Sulphasalazine \\
\hline 17 & Crohn's disease & Absent & Inactive & No disease & No uptake & Sulphasalazine \\
\hline 18 & Ulcerative colitis & Mild & Active & DC, $\mathbf{R}$ & DC, $\mathbf{R}$ & Prednisone 40 mg \\
\hline 19 & Crohn's disease & Absent & Inactive & No disease & No uptake & - \\
\hline 20 & Ulcerative Colitis & Severe & Active & AC, TC, DC, R (colonoscopy) & AC, TC, DC, R & Prednisone $60 \mathrm{mg}$ \\
\hline
\end{tabular}

$\star \mathrm{TI}=\mathrm{Transverse}$ ileum. $\mathrm{AC}=$ Ascending colon. $\mathrm{TC}=\mathrm{Transverse}$ colon. $\mathrm{DC}=$ Descending colon. $\mathrm{R}=$ Rectosigmoid.

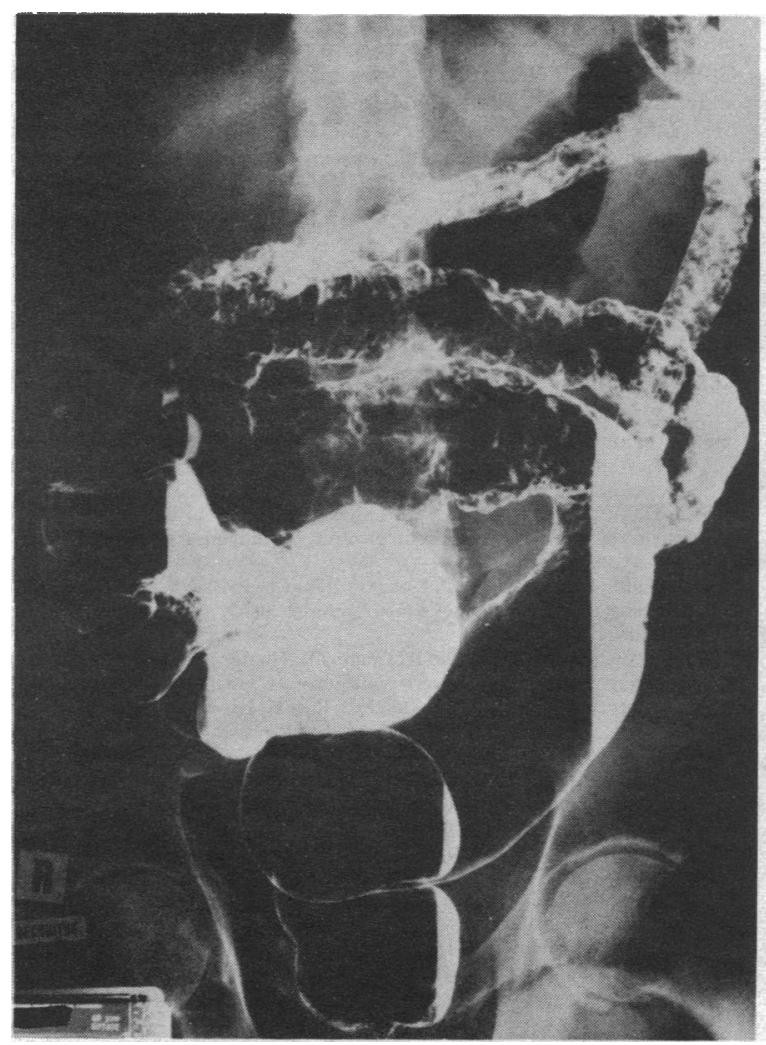

which is inaccessible to colonoscopy and often poorly visualised by barium examination. The ${ }^{99 m} \mathrm{Tc}$ phagocyte scan, like colonoscopy, detects active inflammation-a distinction not made by barium examination, in which the mucosal abnormalities outlined may represent fibrosis or other changes due to previous disease that is no longer active.

Several scanning techniques have been developed to exploit the advantages of radionuclide scans in identifying active inflammatory bowel disease. Gallium-67 scans require 24 to 48 hours before images can be interpreted reliably, and false positive results arise because of normal bowel excretion. Subsequently, "IIn-oxine leucocyte scanning has been shown to provide earlier images, to distinguish inflamed bowel from abscess more readily, and to allow faecal excretion of labelled cells to be measured for assessment of disease activity. ${ }^{5}$ Recently, a new test entailing oral administration

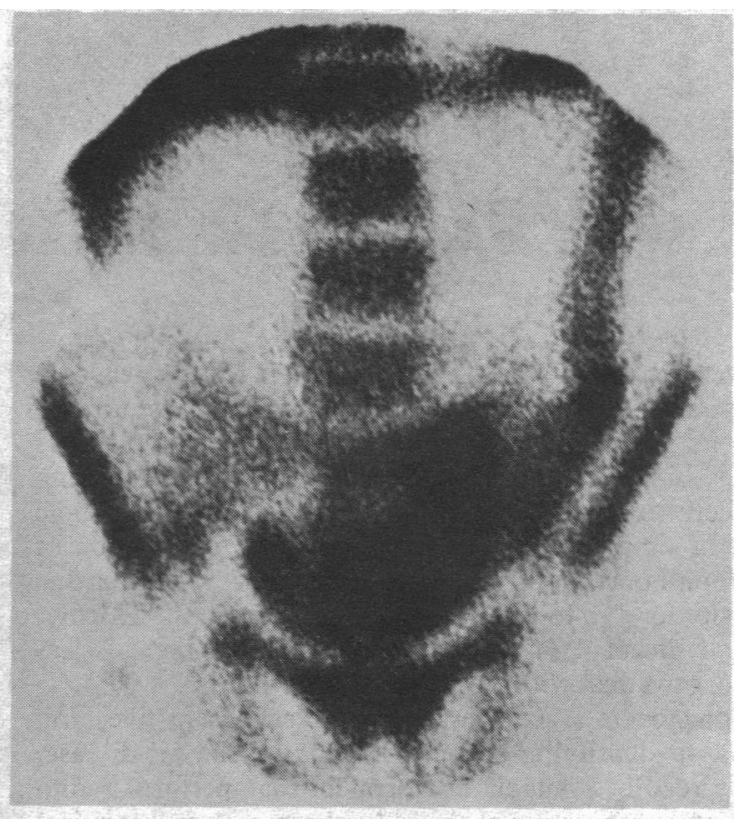

FIG 3-Three hour ${ }^{99 m}$ Tc phagocyte scan compared with barium enema examination performed four days later in a patient with ulcerative colitis. The scan shows pancolitis, but sparing of the rectosigmoid region is suggested by the barium study. Evidence of active mucosal inflammation of the rectosigmoid region was confirmed by histology.

of sucralfate to detect mucosal inflammation has been reported." This method, however, is unsuitable for use in the acutely ill patient and cannot readily be used to assess disease activity objectively. Moreover, the test depends on bowel transit of isotope and is therefore probably of limited value when there is partial bowel obstruction or greatly increased motility.

${ }^{99 m}$ Tc phagocyte scanning shares several important advantages

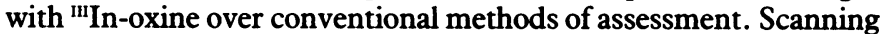
entails minimal preparation and discomfort for patients and can be used in the acutely ill patient. Furthermore, disease activity can be assessed objectively. Preliminary studies in our patients indicate that inflammatory activity can be measured objectively from both temporal uptake of radioactivity with regional analysis ${ }^{12}$ and faecal excretion of isotope (preliminary observations).

The ${ }^{99 m}$ Tc phagocyte scan reported here has several important 


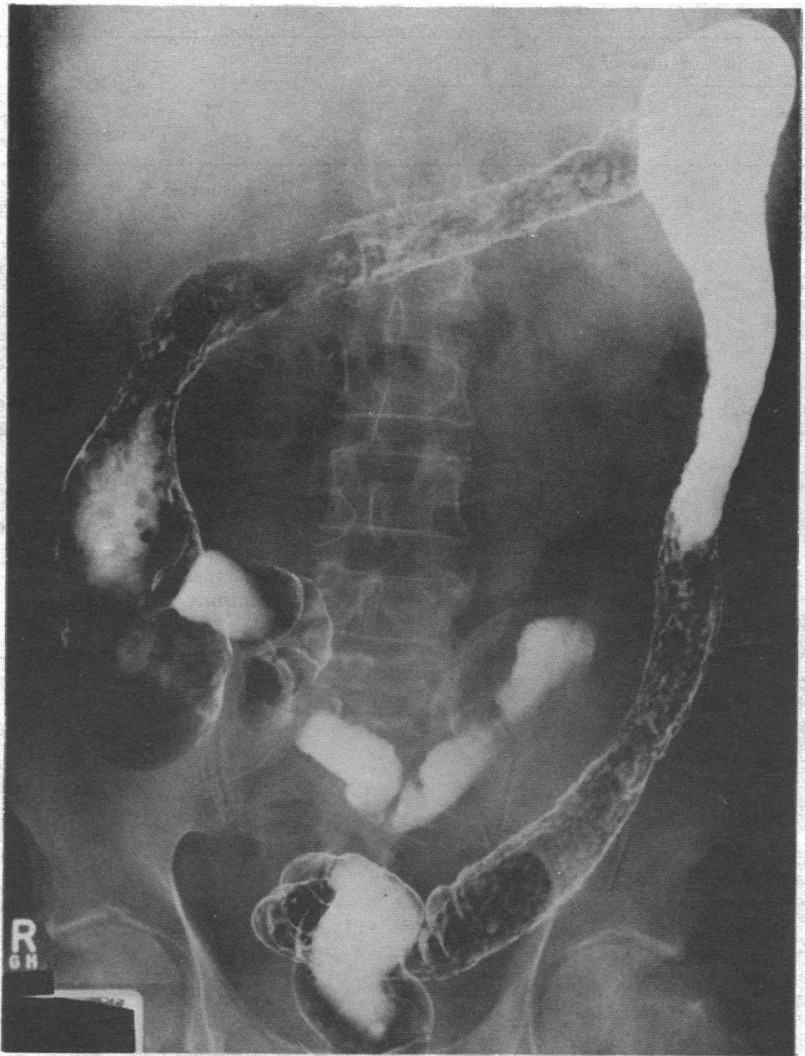

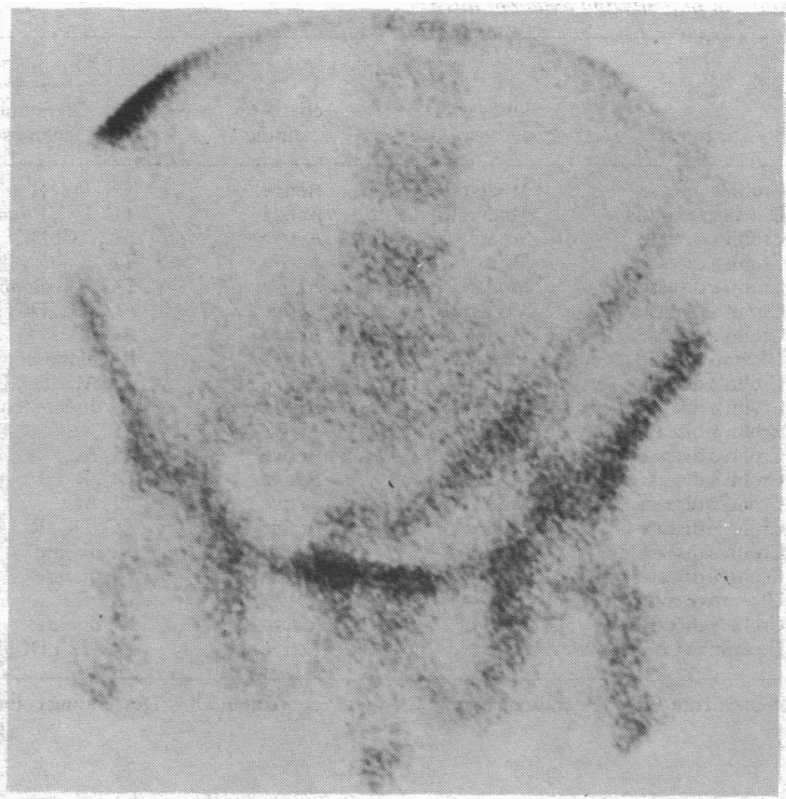

FIG 4 -Six hour ${ }^{99 m} \mathrm{Tc}$ phagocyte scan in a patient with longstanding Crohn's disease compared with barium enema examination Extensive mucosal abnormalities apparently affecting the entire colon are seen in the barium study, but the scan suggests that active inflammation is confined to the descending colon and rectosigmoid regions. advantages over "IIIn-oxine scans. Firstly, ${ }^{99} \mathrm{Tc}$ is readily available in hospitals and is fairly inexpensive, whereas "II requires a cyclotron for its generation and is very expensive, and thus its practical use is limited. Secondly, the ${ }^{99 m} \mathrm{Tc}$ tin colloid labelling technique selectively labels neutrophils and monocytes in whole blood. This is a simple method that obviates the preparation of purified neutrophil populations required for optimal "IIn scans due to the propensity for 'In to label all the blood cell types. ${ }^{6}$ Thirdly, the shorter half life of ${ }^{99 \mathrm{~m}} \mathrm{Tc}$ (six hours) means that there is less irradiation of organs than with "'In (half life 67.5 hours).

The ${ }^{99 m} \mathrm{Tc}$ phagocyte scan offers a cheap, safe, sensitive, and reliable means of identifying active inflammatory bowel disease. The isotope is readily available in hospitals that perform radionuclide scans, and preparation of the radiopharmaceutical requires minimal technician time.

This study was supported in part by the Ileitis and Colitis Fund of the Australian National University and the National Foundation for Ileitis and Colitis of New York. We thank the staff of the departments of nuclear medicine of Woden Valley and Royal Canberra Hospitals for their help, especially Mr J Lissing. We also thank Drs A C Clarke, W A Davies, L Hillman, and M C Ngu for allowing us to study their patients and the photography department of John Curtin School of Medical Research and Mrs M Tunks for their expert help.

\section{References}

1 Saverymuttu SH, Peters AM, Hodgson HJ, Chadwick VS, Chadwick JP. Indium-III autologous leucocyte scanning: comparison with radiology for imaging the colon in inflammatory bowel disease. $\mathrm{Br} \mathrm{Med} \mathrm{f} \mathrm{1982;285:255-7.}$

2 Stein DT, Gray GM, Gregory PB, Anderson M, Goodwin DA, McDougall IR. Location and activity of ulcerative and Crohn's colitis by Indium III leucocyte scan. Gastroenterology 1983;84:388-93.

3 Saverymuttu SH, Lavender JP, Hodgson HJF, Chadwick VS. Assessment of disease activity in inflammatory bowel disease: a new approach using ${ }^{\text {IIIn granulocyte scanning. } \mathrm{Br} \text { Med }}$ 1983:287:1751-3.

4 Buxton-Thomas MS, Dickinson RJ, Maltby P, Hunter JO, Wraight EP. Evaluation of Indium scintigraphy in patients with active inflammatory bowel disease. Gut 1984;25:1372-5.

5 Saverymuttu SH, Peters AM, Crotton ME, Rees H, Lavender JP, Hodgson HJF, Chadwick VS IIIIndium autologous granulocytes in the detection of inflammatory bowel disease. Gu 1985;26:955-60.

6 Saverymuttu SH, Peters AM, Lavender JP, Hodgson HJF, Chadwick VS. "IIIndium autologou leucocytes in inflammatory bowel disease. Gut 1983;24:293-9.

7 Thakur ML, Lavender JP, Arnot RN, Silvester DJ, Segal AW. Indium- ${ }^{\text {III-Labelled autologous }}$ leucocytes in man. I Nucl Med 1977;18:1014-21.

8 Hanna R, Braun T, Levendel A, Lomas F. Radiochemistry and biostability of autologous leucocytes labelled with ${ }^{99 m} \mathrm{Tc}$-stannous colloid in whole blood. Eur f Nucl Med 1984;9:216-9. Schroth MJ, Oberhausen E, Berberich R. Cell labelling with colloidal substances in whole blood. Eur Y Nucl Med 1981;6:469-72.

10 De Dombal FT, Burton IL, Clamp SE, Goligher JC. Short term course and prognosis of Crohn's disease. Gut 1974;15:435-43.

11 Dawson DJ, Khan AN, Miller V, Ratcliffe JF, Shreeve DR. Detection of inflammatory bowel disease in adults and children: evaluation of a new isotopic technique. Br Med f 1985;291:1227

12 Pullman WE, Hanna R, Sullivan P, Booth T, Lomas F, Doe WF. Technetium ${ }^{99 m}$ autologous leucocyte scanning in inflammatory bowel disease. Aust NZ $\mathcal{J}$ Med 1985;15:544.

(Accepted 14 April 1986) 